\title{
Mindset shifts for the Fourth Industrial Revolution: Insights from the life insurance sector
}

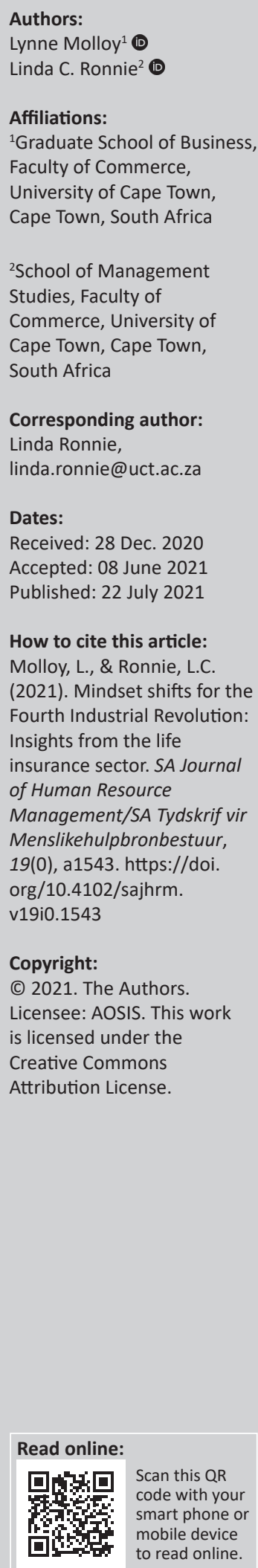

Orientation: The Fourth Industrial Revolution (4IR) challenges organisations to embrace and adapt to a rising wave of technological innovation to remain relevant.

Research purpose: Based on the interaction between technology change, the industry as a whole and the perceptions of individuals within organisations, this study explored how South African life insurance companies view the 4IR and how they are responding to the changes prompted by it.

Motivation for study: This study sought to establish a baseline for practitioners in the life insurance industry to navigate the 4IR more effectively and for researchers to undertake further inquiry into specific enablers and inhibitors of technology transformation.

Research approach/design and method: The study took an exploratory, qualitative approach. Interviews were conducted with 12 organisational leaders, purposively selected from a range of large, medium and start-up life insurers in South Africa. A thematic analysis method was used to analyse the data.

Main findings: Four key themes related to organisational change and resistance to change within the industry were found: lack of urgency; lack of agility; partnerships and ecosystems; and abilities of people and leaders.

Practical/managerial implications: Managers should recognise the urgency for proactive change, encourage collaborative practices by leveraging ecosystems and forming partnerships and ensure lifelong learning of employees.

Contribution/value-add: There is a paucity of empirical work on managerial perceptions of the 4IR and the readiness for change within the life insurance industry. This study contributes to this debate and provided insights on organisational views at a management level.

Keywords: the Fourth Industrial Revolution; technological innovation; life insurance; organisational change; change readiness; resistance to change.

\section{Introduction}

Society and business are increasingly contending with the rising wave of technological innovation known as the Fourth Industrial Revolution (4IR) (Davis, 2016; Roblek, Meško, \& Krapež, 2016; Whysall, Owtram, \& Brittain, 2019). This transformative phenomenon has begun to drastically alter the way that businesses operate, introducing a significant threat to those that resist it and a sizeable opportunity to those that embrace it. To date, the life insurance industry has managed to evade this change because of the highly complex and specialised nature of the industry (Catlin \& Lorenz, 2017). However, an evasion strategy is quickly becoming unrealistic as life insurers face increasing pressure from consumers and other stakeholders who are expecting a level of service and digitisation that aligns with their experience of other industries (Bose \& Bastid, 2018; Malherbe \& Dixon, 2017).

Although there is a common perception that the insurance industry is technology avoidant, insurance companies have been attempting to increase and expand their internal digital capabilities. This metamorphosis occurs through leveraging a range of technologies, from wearable devices to machine learning (Bose \& Bastid, 2018; Bughin, Laberge, \& Mellbye, 2017). However, although companies within the industry have developed multiple innovations like these in isolation, the industry as a whole has yet to take a more integrated approach to technology adoption to shift the fundamental business model. This is happening as a new cohort of tech startups is entering the market under the banner of InsurTech. As more InsurTech start-ups emerge, incumbent firms that fail to recognise and engage with the 4IR run the risk of losing market share, 
workforce obsolescence or business model disruption. In a country that has become increasingly dependent on the growth of the financial services sector for gross domestic product (GDP) growth and faces extreme unemployment, this loss of ground for incumbents can have devastating results for the country as a whole.

\section{Research purpose and objectives}

South Africa is not alone in its struggle to navigate the exponential change of the 4IR. Increasing investment and movements towards InsurTech in North America and Asia over the last 2 years (Holliday, 2019) mean that learnings from the global insurance industry's approach to the 4IR may be instrumental in guiding the way forward for South Africa. Understanding the current attitudes and reactions of South Africa's life insurance companies towards the 4IR is an important step in incorporating global learnings to prepare the local industry and workforce for the future. This study therefore explores the views of leaders from a diverse group of local life insurance companies to understand how these organisations define the 4IR, their perceptions of its effects on the industry and their own responses to the 4IR to date.

Canning and Found (2015) find that when organisations understand the causes of resistance to change, they can create change programmes that are better suited to their organisations. This study aims to create greater understanding by examining the interaction between technology change, the life insurance industry as a whole and the perceptions and actions of individuals within South African insurance companies through the following research objectives:

- what organisations understand by the 4IR,

- the perceived effects of the 4IR on the South African life insurance industry and

- what responses organisations have had to the 4IR and the reasons for these.

This inquiry serves to establish a baseline for practitioners in the life insurance industry to navigate the impact of the 4IR more effectively and for researchers to undertake further inquiry into specific enablers and inhibitors of technology transformation in the industry.

\section{Literature review}

\section{South African life insurance}

Although South Africa is an emerging market, the formal life insurance industry dates back to 1845 and is considered to be a mature market (Malherbe \& Dixon, 2017). South Africa has the third highest life insurance penetration rate in the world, and in 2016 the industry was ranked 16th in the world in terms of annual earnings from insurance premiums (Axco, 2018). Furthermore, the local industry has contributed many innovations to the global industry, including the development of critical illness products, products for individuals living with human immunodeficiency virus (HIV) and mobile insurance propositions. The regulatory environment within the industry has closely tracked advances in leading insurance markets as evidenced by the transition to a riskbased solvency model, which is similar to the European Solvency II, and the globally trend of consumer protection initiatives such as Treating Customers Fairly and the Retail Distribution Review. This perspective suggests a market that is comparable to developed insurance markets across the globe. However, this position is challenged by another side to the market, which is characterised by typical emerging market features. With an unemployment rate of $27.6 \%$ (Statistics South Africa, 2019) and a Gini coefficient of 0.63 (World Bank, 2018), South Africa has one of the most unequal societies in the world. This inequality creates a dichotomy of demand in the insurance market with affluent consumers demanding solutions akin to those found in developed markets and impoverished consumers requiring simple assistance or micro-insurance solutions. Moreover, socioeconomic disparities fuel mortality and morbidity risks as well as higher transactional costs of insurance provision, which contribute to more costly local insurance offerings and may serve to impede innovation efforts because of affordability concerns (Swiss Re, 2017). The outcome is a hybrid insurance market that is comparable to leading developed markets on the one hand, but distinctively influenced by a broader developing market context on the other hand.

As the rise of FinTech in the financial services sector in subSaharan Africa has demonstrated, technology-led transformation can present a major opportunity for increasing access and penetration within less developed markets that were under-served by traditional business models (Arner, Barberis, \& Buckley, 2015). The lack of infrastructure in these markets is often cited as an enabler of exponential technological change that favours emerging markets as sites of change over developed countries, the so-called 'leapfrog' phenomenon. Although small start-ups have largely led the way for transformation in FinTech, as in any of the emergent '-Tech' sectors, the need for partnership of some kind between these new players and the incumbent providers is seen as essential (Arner et al., 2015; Okada, 2018). Consequently, life insurance firms need to engage with the various opportunities and threats presented by the 4IR.

\section{The impact of the Fourth Industrial Revolution}

When the 4IR largely connotes a wave of automation and robotisation, the broad implications of this transformation hold across industries and geographies. The far-reaching nature of this wave has led to a common association of workplace automation with extensive job losses and the obsolescence of human capital (Peters, 2017; Schwab, 2016a; World Bank, 2019). However, in their interview with Bernstein and Raman (2015), Brynjolfsson and McAfee pointed out that only a particular segment of the workforce is at a high risk of displacement, namely middle-class workers with medium-level skills (i.e. those who do not possess highly technical skills to do intensely creative work, but also do not perform low-level manual labour). This has resulted 
in what they have coined 'the Great Decoupling', which describes the ongoing pattern where economic productivity continues to climb (albeit at a slower rate), although family earnings and employment rates have stagnated. This disparity demonstrates a decoupling of what these researchers refer to as the 'two halves of the cycle of prosperity' (Bernstein \& Raman, 2015, p. 69).

In South Africa, skills mismatch, which emanates from the difference between what tertiary education institutions are teaching young people and what employers demand, is often highlighted as a major bottleneck for industry and economic development (Dessus, Goddard, \& Hanush, 2017). The tendency for this mismatch to play out across socio-economic and racial divides in South Africa negatively impacts the country's social cohesion. This pattern could be exacerbated by technology advances or alternatively improved by it (Chetty, 2018). This is critical as Schwab (2016b) warns that the divide between low- and high-skilled workers 'is a recipe for democratic malaise and dereliction' unless organisations plan ahead to forecast future skills requirements (Whysall et al., 2019). The threat to democracy and stability is acute in South Africa where policies have failed to sufficiently address the determinants of gaps in skills, economic opportunities and income that are rooted in apartheid-era policies. These determinants include poor education, crime and access to technology, among others. For instance, in 2011, only $29 \%$ of adult South Africans had completed formal secondary education (Chetty, 2018). This can present a major barrier to an industrial transformation that is dependent on technological infrastructure and a high-skilled workforce.

A more optimistic view of technological transformation acknowledges that humans will continue to be superior in vital skills such as creativity, interpersonal relations and dexterity (World Bank, 2019). Although jobs and workplaces may change, human involvement will remain core to economic activity given the human adeptness for tasks that require perception, social intelligence or creative intelligence (Frey \& Osbourne, 2017). Recent surveys suggest that the rising workforce shares this optimism. A 2019 survey of millennial workers from 42 different countries, including South Africa, showed that $49 \%$ of respondents felt that the 4IR technologies would augment their jobs, whereas 15\% felt that it would have no effect (Deloitte, 2019a). Yet, within the South African cohort, $58 \%$ still felt that the 4IR would make it more difficult to get or change jobs, whereas $12 \%$ said that they did not have any of the requisite knowledge or skills to keep pace with the 4IR work environment (Deloitte, 2019b). This view is shared by global industry executives; in a 2019 survey, 55\% reported skills mismatch as the top challenge related to talent management in the context of the 4IR (Deloitte, 2019c). Currently, many of these organisations rely on the external education system to provide jobs training. However, industry experts suggest that businesses must adopt a continuous learning mindset if they are to keep up with external changes (Bender \& Willmott, 2017; Spelman \& Weinelt, 2018).
In South Africa, the incentives for and abilities of companies to adopt a continuous learning mindset may be limited by other external factors. The insurance industry in South Africa, like other entrenched sectors such as telecommunications and banking, is fairly oligopolistic. The high concentration of the markets in these sectors makes it difficult for new entrants to challenge the status quo with innovation of any kind (Chetty, 2018). An example that is particularly relevant for both incumbents and challengers is Telkom's monopoly within the South African telecommunications sector, which severely inhibits the availability of affordable, high-quality data services in the market. Telkom's hold on the market contributes to the under-developed state of infrastructure in the country, which shapes the models financial service providers and insurers use to deploy innovation effectively (Arner et al., 2015). As of 2016, only 9.5\% of South African households had Internet access (Independent Communications Authority of South Africa, 2018), which limits online penetration in these markets, or at least pressures insurance providers to think more creatively out of the box to market and distribute their services. These contextual factors create an environment within which significant organisational change must take place.

\section{Resistance to change}

To understand how an industry perceives and reacts to the impacts of the 4IR, it is useful to draw on the literature related to past technological changes and how industries and organisations perceived them. Technology changes like those presented by the 4IR could be thought of as 'jolts' that destabilise the organisational field (Lewis, 2019). Organisations would be expected to respond with organisational change action either because they feel forced to respond to a threat, or they choose to seize an opportunity (Singh, Saeed, \& Bertsch, 2012). However, Lewis (2019) explains that jolt events do not carry objective meaning. They are rather subject to the interpretations of people in organisations, who may view them as threats, opportunities or irrelevant, or may not see them at all. If people in an organisation recognise the 4IR as either an opportunity or threat that demands change action, the scale and magnitude of the organisational change implied can be daunting and therefore spur resistance to change. This resistance can manifest at the organisational, group or individual level (Singh et al., 2012). This study is primarily concerned with change at the organisational level, which includes the decision of a business to adapt its models, processes and culture in response to technology change. However, an organisation's ability to change, either because of factors beyond the firm's control or as part of a planned implementation process, can be shaped by resistance at the individual and industry level.

\section{Change management}

Effective technological transformation requires organisations to have a culture and practices that promote 
continuous learning. Cultivating this kind of internal organisational learning is necessary to keep up with digitalisation, which focusses on best practices and knowledge development within the company (Kuusisto, 2017), and will require internal changes in core capabilities and culture. This introduces the need for change management, as Coetzee and Stanz (2015) agree: 'if change is unavoidable, it needs to be manged to serve the best interests of the organisation' (p. 76).

However, traditional notions of change management as a linear, planned process, as per the Lewin three-stage model of change, may be insufficient in the light of a rapidly changing and increasingly uncertain operating environment that can lead to emergent behaviours within the organisation (Lord, Dinh, Hoffman, \& Burke, 2015). As a primary example, resistance to change among individuals, which can be experienced very differently from person to person and for a variety of reasons, can create barriers-to-change within the organisation that impedes change management strategies (Coetzee \& Stanz, 2015). Resistance to change is not only an individual reaction to internal changes, such as culture shifts, new processes or new capability requirements. People can also be resistant to external changes in their institutional contexts, such as those brought on by technology change, which reflects the external organisational learning abilities of the firm (Kuusisto, 2017).

In his analysis of the failed mini-computers developer Digital Equipment Corporation (DEC), Lewis (2019) described how this market leader with vastly superior technological capabilities nevertheless 'lost' the personal computer race to International Business Machines (IBM) Corporation because it failed to adapt to institutional changes in the industry. As Hinings, Greenwood, Reay and Suddaby (2004) explained, businesses in mature industries tend towards organisational isomorphism (DiMaggio \& Powell, 1983) where they adopt the same archetypal template of structures, activities and practices. If a new archetype emerges within the industry and is adopted by others whilst the old archetype loses legitimacy, the institutional context fundamentally changes. The case of DEC represents a scenario where the organisation does not recognise the 'jolt' within their field and suffers the consequences. It is therefore important for organisations to understand how and why people within an organisation resist change to successfully manage such transformational change in the external environment and create suitable internal change management programmes (Canning \& Found, 2015).

\section{Summary}

Given that the concept of organisational resistance to change makes provision for the role of individual and industry factors in responding to a change event and managing change, it provides a useful lens for exploring the perceptions of the South African insurance industry to a jolt event like the 4IR. Figure 1 shows a representation of external transformative

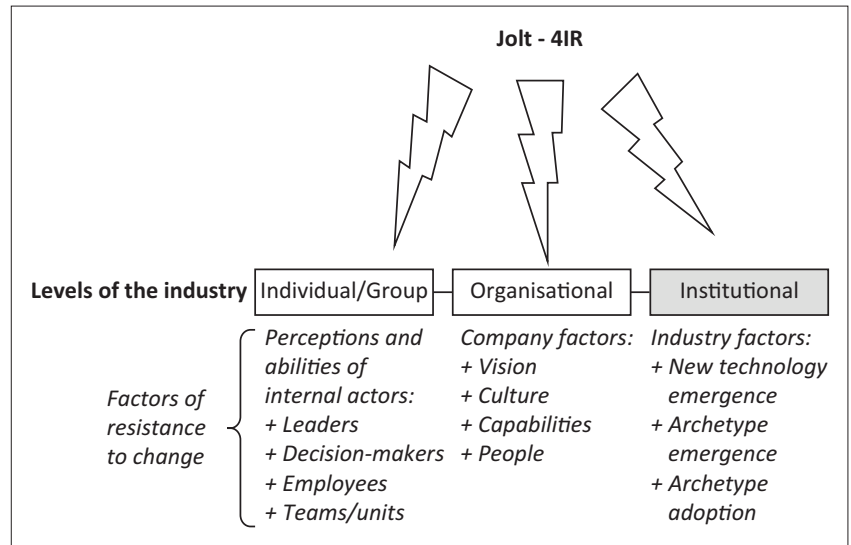

$4 I R$, the Fourth Industrial Revolution.

FIGURE 1: Representation of change introduced by the Fourth Industrial Revolution on the insurance industry.

change to inform the methodology, where the overall industry response is broken into the factors that influence resistance to change at the different levels of the industry (individual or group, organisational and institutional).

Although the literature review establishes that at the institutional level, the industry is objectively not adopting new archetypes at scale as a response to the impacts of the $4 \mathrm{IR}$, this study is interested in exploring the subjective perceptions that people within insurance companies may have of the same phenomenon. This lays the foundation for a research methodology that explores resistance to change in an industry through the perceptions of individuals. The framework also establishes the important internal and external factors that should be included in the research questions.

\section{Research design and methods Overview}

This study examines a specific phenomenon that is the product of the current state of global and local technology adoption and the internal dynamics of an industry. It is, consequently, under-researched, with few studies available that address the wider 4IR phenomenon, the South African context and the local life insurance industry. Exploratory approaches are useful for studying situations such as these, where little is known about the phenomenon (Gray, 2017). Given the study objectives to describe, explain and explore a complex situation, a qualitative, exploratory research strategy was used (Leedy, Ormrod, \& Johnson, 2019) that would allow people who are closest to the situation to provide descriptive data. The research design therefore included structured interviews with senior employees at an array of different South African life insurance organisations by using an interview schedule that explored the different components of the change from the literature review. An inductive approach to data analysis was used to formulate meaning from their responses and relate the emergent themes to the research objectives. 


\section{Research participants and sampling method}

The target population for this study was senior employees within the South African life insurance companies who would have access to information related to company vision and leadership that junior employees might not. Guidelines from Leedy et al. (2019) were applied to derive the selection criteria, namely the inclusion of both typical and nontypical examples and the inclusion of a diverse group of organisational environments. The participants were therefore all executive-level decision-makers from multiple organisations that were diverse in terms of size, maturity and the degree of technological integration (i.e. a traditional insurance company compared with an InsurTech firm). Publicly available information on the company websites was used to identify organisations that would meet the criteria, and participants were approached directly by the researchers.

Guest, Bunce and Johnson (2006) propose the use of data saturation for non-probabilistic sampling to determine the optimal number of interviews required to obtain valid results. Saturation is reached when no additional themes emerge from the interviews. In this study, data saturation was reached after 12 interviews. This group of interview participants was from eight organisations: five large and established organisations and three small, medium-sized or start-up organisations. The participants held various senior leadership roles in their organisations; the sample included three chief executive officers (CEOs), two technology executives, four directors of established business operations and three directors focussed on emerging business operations (Table 1).

\section{Data collection procedure}

Structured interviews with organisational representatives were used to address the three research objectives, which broadly aimed to explore the response of the South African insurance industry towards the impacts of the 4IR. Building on the concepts of resistance to change and change management, the interview questionnaire consisted of three sections that reflect the three levels in which resistance to change can take hold:

\begin{tabular}{lll} 
TABLE 1: & Participant descriptions. \\
\hline Participant alias & Organisation type & Function \\
\hline Andrew & Small insurer & CEO \\
Brad & Large insurer & Technology executive \\
Clark & Medium-sized insurer & Established business focus \\
Dan & Large insurer & Emerging business focus \\
Ewan & Large insurer & Established business focus \\
Frank & Large insurer & Established business focus \\
Greg & Large insurer & Technology executive \\
Hugo & Large insurer & Emerging business focus \\
lan & Small insurer & CEO \\
John & Large insurer & Established business focus \\
Kelvin & Large insurer & Emerging business focus \\
Kirk & Small insurer & CEO \\
\hline
\end{tabular}

CEO, chief executive officer.
- Industry assessment (institutional level) - general definition of the 4IR and effects on the South African insurance industry.

- Company description (organisational level) - vision, capabilities, culture and people.

- Leadership (individual level) - views, actions and abilities of leaders.

The full questionnaire is provided in Appendix 1. The initial question, which asked participants to define the 4IR, served to establish their familiarity with the concept and ensure that their understanding was in line with the one in this study, that is, seeing the 4IR as a technological transformation or a jolt event. Within the company and leadership sections, the questions were selected to probe general aspects of the organisation and leaders, before exploring how these aspects respond (or do not respond) to technological transformation. This was performed explicitly to, for instance, determine how the organisation's current vision did or did not respond to the 4IR. A pilot interview was conducted with a mock participant of a similar profile to the sample population prior to performing the official interviews to test the research instrument. The pilot was used to refine the wording to make the questions clearer and remove any potentially leading wording from the final questionnaire.

Data collection took place from September to November 2018. The interviews were held at the participants' places of work in a quiet space to avoid distraction, create a situation in which participants felt comfortable (Quinlan, Babin, Carr, Griffin, \& Zikmund, 2015) and develop an informal rapport with participants whilst asking interview questions (Bryman \& Bell, 2015). Participants had been contacted and invited to participate in the study via email in the month prior to the interview. After participants agreed to participate, interview dates were scheduled, and written informed consent was obtained from participants on the day of the interview, prior to the data collection. All interviews were audio-recorded by using a smartphone device and stored securely on a file for later transcription. Interview transcriptions were used to code and analyse the data.

\section{Strategies to ensure data quality and integrity}

There are two perspectives from which to explore validity in qualitative research, namely internal validity and external validity. To strengthen internal validity, researcher reflexivity is recommended (Leedy et al., 2019). Given that one of the researchers actively participated in the life insurance market for several years prior to this study, biases were likely to exist. These biases include perceived resistance to change within the researcher's organisation and concern about the need for insurance companies to be more proactive about technological change. An attempt was made to identify these biases prior to interviews and to actively suspend them during interviews as well as during the analytical process. Although the researcher cannot claim to have excluded all possible bias, every effort was made to minimise this through 
presenting interview questions neutrally and consistently to all interviewees and seeking agreement from each interviewee to validate the findings. Interviewees were therefore involved in the validation process and asked to check the accuracy of the data (Bryman \& Bell, 2015).

To strengthen external validity, Leedy et al. (2019) recommend that researchers explore exceptions and contradictory evidence to guard against the tendency to identify patterns that are consistent with existing, ingrained beliefs. This was achieved, in part, through the sample selection. The sample included participants who held a variety of traditional and nontraditional decision-making roles within the organisation. It also included a combination of people in more technology and innovation-oriented teams and people focused more on operation optimisation to ensure diversity of perspectives. In addition, the researchers explored unusual responses with interviewees as they arose by asking follow-up questions.

In terms of transferability, methodologists caution against extending current conditions to some period in the future (Gray, 2017). This view is particularly relevant for this area of research where the business and technological environments are rapidly changing. Findings are likely to be limited in their transferability to within a short- to medium-term time frame.

\section{Data analysis}

An inductive approach to thematic analysis was taken to uncover emergent themes from the interview and observational data. Creswell's (2013) data analysis spiral was used to analyse the data with the following steps.

Data organisation: The transcribed data from the interviews and researcher notes were organised in a digital database, where large segments of the text were dissected into smaller units of anecdotes, phrases and words. This approach was used to screen the data units for emerging themes.

Data review: The process of manually reviewing the data allowed the researchers to form initial impressions of the data. An initial coding template was constructed from notes taken during this review.

Data classification: Following the data review, King and Brooks' (2017) approach was used to develop a coding template by identifying, colour-coding and separating general categories, themes, subcategories and subthemes. Through this process, the researchers were able to develop a sense of patterns and underlying meanings in the data set. The initial coding template provided a starting point for the final coding template that was developed by manually incorporating the remaining six interviews and cycling iteratively through all interviews.

Data synthesis: Primary themes linking the different codes and categories were developed from this coding template. The researchers took care to carefully define the themes and align them with interviewee responses. This process created an opportunity to scrutinise each theme for distinctiveness and relevance. The synthesis process transformed specific outcomes into more general and holistic findings to provide a basis for developing conclusions and recommendations.

\section{Limitations of the study}

Compared with quantitative research, qualitative research is often criticised for having small sample sizes, using nonprobabilistic techniques and offering results, which may be coloured by the experience and perspective of the researcher, all of which undermine the generalisability of the findings. Although broad generalisation is unlikely to be achievable, particularly given the distinctiveness of the South African life insurance industry, Gray (2017) suggests that a limited set of generalisations may be applicable in moderation to a specific or related context. However, given the rapidly changing business and technological environment created by the 4IR, it is expected that both the generalisability and transferability of the findings of this study will be limited to the specific sector and short- to medium-term time frame.

\section{Findings}

The thematic analysis produced distinctive primary and supporting themes within the data set, which are summarised in Table 2.

\section{Lack of urgency}

The 4IR is something that participants largely recognise as an attractor of new competitors, as well as an enabler of their ability to be more client-centric. However, the impact of this revolution in the South African life insurance to date was unanimously agreed to be minimal. Although all 12 participants admitted to a sluggish response to the 4IR in their own organisations, half of the participants qualified this response by acknowledging that this slow, measured response was intentional. One-third of participants further

\begin{tabular}{lc} 
TABLE 2: Summary of themes. & Frequency \\
\hline Primary themes and sub-themes & 12 \\
\hline Lack of urgency & 6 \\
Intentional & 3 \\
Lack of market readiness & 6 \\
Inability & 11 \\
Lack of agility & 8 \\
Structural inertia & 6 \\
$\quad$ Legacy systems & 4 \\
Protection mechanisms & 6 \\
Cultural inertia & 6 \\
$\quad$ Execution ability & 5 \\
Risk aversion & 4 \\
$\quad$ Actuarial profession & 8 \\
Partnerships and ecosystems & 12 \\
Abilities of people and leaders & 8 \\
People as enablers of innovation & 12 \\
Reactive leaders & 8 \\
Proactive leaders & 9 \\
Lack of internalisation by leaders &
\end{tabular}


suggested that this measured response was necessary because of unpreparedness in the market. Kelvin (large insurer, emerging business focus) said that insurers 'need to go at a pace that the customer is used to. So radicalising technology before a market is ready for it is a wasted use of your energy'.

Although this could be viewed as a generally reasonable approach for any industry in any geography, other respondents pointed out the particular need for slow change in the South African context. John (large insurer, established business focus) noted that many potential customers in South Africa, particularly those within lower socio-economic groups, were not ready to embrace new technologies. John said, 'There's a little bit of an overplay on digital sometimes it doesn't have to always be digital'. This sentiment was reiterated by Kirk (large insurer, emerging business focus): 'You can't just innovate for innovation's sake'. All four participants who pointed to market readiness as a bottleneck further alluded to readiness within the intermediary market. For instance, Clark (medium-sized insurer, established business focus) said, 'We can do exciting stuff on a computer and an iPad, but it seems that a lot of brokers still want paper'.

\section{Lack of agility}

Although six of the interviewees considered the life insurance industry's slow response to the 4IR to be intentional, the other six conceded that this was a regrettable outcome and largely because of a lack of agility. In this study, a lack of agility means that the business is not able to respond quickly to emergent threats or opportunities. Lack of agility was noted by 11 interviewees as the primary inhibitor towards a meaningful progress across the industry, regardless of intention. Dan (large insurer, emerging business focus) said, 'There's lots of opportunity, but nobody is really grabbing the bull by the horns'. Therefore, whether interviewees subscribe to the belief that the measured response to the 4IR is intentional or unintentional, they all recognise that the industry is not moving quickly with respect to technological transformation.

Three sub-themes emerged as drivers of the lack of agility across the industry: structural inertia (eight participants), cultural inertia (six participants) and risk aversion (five participants). Structural inertia refers to the processes, systems and structures in a firm that serves to support and reinforce a certain way of doing things. Speaking to the issue of structural inertia within the (large insurer, established business focus) industry as a whole, Frank said:

'Quite often we are trying so hard just to keep the wheels turning in the current world, that it's hard to imagine what the future world is going to look like.'

Structural inertia is further fuelled by legacy systems (six participants) and industry protection mechanisms (four participants). Legacy systems refer to technology, processes or programmes that are typically both out-dated and deeply embedded in the organisational operations. In describing how inhibiting these legacy systems are, Ian (small insurer, CEO) said, 'A lot of existing insurers have archaic, manual business models. How do they stay relevant to clients in the modern world?' Andrew (small insurer, CEO) described the challenge when trying to change or modernise a legacy system as 'a bit like trying to move a graveyard'.

Industry protection mechanisms refer to the broader industry structures that serve to reinforce structural inertia by raising barriers to entry and thereby limiting competition and/or the need to change. Those mentioned by interviewees include dense and complex regulation, expertise in relation to risk assessment techniques and models, high capital or solvency requirements, new business strain because of the heavily intermediated nature of the market and high upfront commissions and significant data requirements. Greg (large insurer, technology executive) noted the perverse nature of one of these industry protection mechanisms, saying, 'Regulation, despite everything that we complain about, is actually a big favour to insurers'.

Hugo (large insurer, emerging business focus) explained why his company struggles to innovate, saying: 'Because of the dual forces of the antiquated systems and the cultures in which they operate'. He is describing the connection between structural and cultural inertia.

Dan (large insurer, emerging business focus) referred to both cultural inertia and the vested interest of employees who are succeeding in the current operating environment by saying, 'You end up with a lot of stone throwers - people who will try and take this thing down because it's a threat to what they're doing'. One notable component of cultural inertia that emerged from six of the participants as an impediment to agility was execution ability or follow through. 'Innovation is only $20 \%$ of the problem; execution is the other $80 \%$ ', explained Clark (medium-sized insurer, established business focus).

Finally, risk aversion was raised as a contributor to lack of agility by participants. Hugo (large insurer, emerging business focus) suggested that an aversion to risk is reinforced by the prevailing mindset across the life insurance industry which he describes as distinctly 'rational and highly cynical'. Four participants linked this lack of risk-taking to the dominance of the actuarial profession, which values data and evidence-based decision-making, across the life insurance industry. Greg (large insurer, technology executive) said: 'I find it very perverse - the industry is about managing risk, yet it's quite risk-averse'. His words highlighted the paradox that an industry whose business is the management of risk can practise excessive risk aversion to the point that it inhibits its ability to innovate for better risk management.

\section{Partnerships and ecosystems}

The third major theme was the tendency of companies to engage in partnerships and leverage ecosystems to pursue 
technological change. Eight participants said that a partnership mindset was a fundamental requirement to operate in the 4IR. As part of the discussion of partnerships, the word 'ecosystem' was often used as a key interrelated theme. Clark (medium-sized insurer, established business focus) said an ecosystem was 'a collaborative network of people in different domains' that includes 'FinTechs, accelerators, incubators, academic institutions, industry think tanks and global partners in financial services who are non-competing'. Brad (large insurer, technology executive) described the connection between partnerships and ecosystems for the 4IR as follows: 'I think in future we will see more crowd-sourced innovations potentially leveraging an ecosystem of innovation partners to provide a richer offering'.

In this context, an ecosystem consists of a network of organisations and parties from across the industry. A partnership mindset reflects the ability of an organisation to participate in and leverage this network by adopting a collaborative approach with other parties. This attitude runs counter to the current prevailing mindset in the life insurance industry, which Hugo (large insurer, emerging business focus) described as a 'zero-sum mindset' whereby insurance companies 'focus more on making sure that they don't get done in, and that they get that little bit more than you do' when working with allied organisations. Clark (medium-sized insurer, established business focus) further noted this limiting mindset when assessing insurance companies' relationships with FinTech, stating that insurance companies should 'not see them as such a threat, but see them as an enabler and as a potential partner'.

\section{Abilities of people and leaders}

All 12 participants alluded to the role individuals can play in shaping the organisation's response to technological transformation. Eight participants said that people were a key enabler of innovation and exploration activities. More specifically, they refer to people's strength, competencies and ability to inspire action across the business. Andrew said firms select the 'best people' for innovation projects and initiatives. Similarly, Frank (large insurer, established business focus) said that innovation teams should include people who are 'looking for opportunities and can live with the ambiguity and the uncertainty that comes with it'.

Interviewees recognised the power that leaders, and particularly CEOs, have to influence the organisation's response to technological transformation, for better or worse. For example, some participants linked the choice to adopt a partnership mindset to leadership. They said that leaders drive change through their own example by collaborating with others, internally and externally, rather than operating in isolation. Although a partnership mindset is consistently noted as important, firms and leadership teams vary in their ability to adopt this mindset. Ewan (large insurer, established business focus) expressed confidence that his leaders would embrace a partnership mindset:
'From a leadership perspective, I've got huge confidence. I think they're onto the right issues, they are investing the right amount of resources into it and they are leveraging the right clout internationally in terms of partnerships including the giants of technology who we've chosen as global partners.'

Conversely, Kelvin (large insurer, emerging business focus) said that leaders at his company view InsurTech firms as a threat and have little interest in partnerships.

All participants felt that their leaders were focussed on keeping up with technological change, and that they were at least being reactive to new technology. Eight interviewees felt that their leaders were focussed on initiating radical technological change and being proactive about technological transformation. However, in terms of implementation, nine interviewees suggested that their leadership teams struggled to drive exploration and innovation because they did not fully internalise the need to prioritise these kinds of activities alongside business as usual. Brad (large insurer, technology executive) expanded on this same pattern within his firm: 'We've got a very capable team, but not necessarily fully bought into a transformed way of working'.

Greg (large insurer, technology executive) noted that the reasons for lack of buy-in across leadership teams were aversion to change and the destabilising speed of change:

'Humans don't like change, so our tendency is to be more incremental. Many leaders have come from a world where change was something that you went through and then it finished and there was stability. We now live in a world where change is constant. Certainly, one of the biggest mindset shifts involves how we as leaders can adapt.'

\section{Discussion}

\section{Summary of findings}

This study demonstrates that the resistance to change that is clearly present at the institutional level of the broader insurance industry is also present at the organisational and individual levels (Singh et al., 2012). This aligns with Moodley's (2019) findings about resistance to change at the organisational level among the incumbent organisations in his study of InsurTech in South Africa. This study, however, provides greater granularity, qualifying this resistance in terms of the mindsets, norms, structures and culture embedded within life insurance organisations. The findings also demonstrate how these individuals interpret the dynamics in their external environments to reinforce resistance to change at the organisational and institutional levels.

\section{How organisations perceive the Fourth Industrial Revolution and its impacts on their industry}

The responses of participants showed a shared mindset among organisations in the life insurance industry where the $4 \mathrm{IR}$ is viewed as a set of technology-based tools that 
provide a means to an end, rather than a transformational movement that is re-shaping the industry and economy more broadly. Yet, when participants discuss their industry in terms of ecosystems and partnerships, there is clear recognition that an institutional transformation will stem from the 4IR. The breadth and depth of industry protection mechanisms appear to be offering these organisations respite, but as the efficacy of these mechanism fades, the urgency for change will become more pressing. This view of the 4IR as a tool to be wielded by incumbents runs counter to Schwab's (2016a) characterisation of the 4IR as an amalgamation of technologies across physical, digital and biological spheres that enables leaders to transcend their individual application to drive a more extensive and fundamental change in business operations. The narrower perspective expressed by the participants, who are also leaders within their companies, may prove problematic for their future innovation. Recalling Lewis (2019), they may fail to fully recognise and respond to the jolt of InsurTech within the institution of insurance.

\section{How organisations are responding to the Fourth Industrial Revolution}

Participants in this study recognised the role of the external environment in shaping both the impacts of the 4IR in South Africa and a resistance to change within their organisations. Yet, one reason insurance companies may be failing to see the 4IR as an institutional jolt is that they are looking at their industry in isolation. Customer expectations of all services, including insurance, are changing because of the technological advancements made in other industries, such as mobile banking in the financial services sector (Bose \& Bastid, 2018; Camarate, Smit, Van Rooyen, \& Chimbuya, 2017). Yet, this view was noted by only three participants and was countered by the argument that South Africa as a whole is delayed in its appetite for digitisation. For instance, the preference of brokers to use pen and paper over computers is very likely a reflection of contextual factors in South Africa related to poor computer literacy on the part of customers or insufficient access to technology.

Even if this is the case, the state of development in the market does not invalidate the decision to innovate. If anything, as the trajectory of FinTech would suggest, it should drive innovation (Arner et al., 2015). For instance, Moodley (2019) points to the potential of value-based InsurTech to meet the unique needs of these 'unready' markets in South Africa. The reactive approach to the 4IR supported by half of interviewees seems ill-advised in the light of the rapid speed of change and need for urgent responses described in the literature (Bose \& Bastid, 2018). Further, Tushman, O'Reilly and Harreld (2015) note the importance of leading proactive, punctuated change rather than ignoring the tide, which forces organisations to respond reactively and less effectively. Using this argument, a lack of market readiness may be a pretext that insurers use to justify their protracted reactions and ultimately a lack of agility.
The responses from participants in this study affirm the role of institutional factors in creating resistance to change within organisations. The structural and cultural inertia they highlight is nuanced and fortified across the South African life insurance industry. Participants are effectively describing the organisational isomorphism that creates dominant archetypes and at least gives the appearance of a stagnant and uniform industry (Hinings et al., 2004). Although the mechanisms of inertia and isomorphism outlined by participants align to those described in the literature, the impact of these mechanisms was expanded by participants' novel interpretation of them. Participants described how some of the most powerful industry protection mechanisms, which serve to sustain the industry - such as dense regulation, high capital requirements and impenetrable distribution networks - are not necessarily appreciated as such and instead limit and frustrate organisations. Similarly, cultural inertia sustained by a normative aversion to risk, which stems from the prevalence of actuarial professionals and serves the goal of risk management, was said to inhibit the imperative to innovate and therefore embrace the 4IR. A willingness to take risks is noted as an enabler throughout innovation literature (Adler et al., 2009; Dorado, 2002) as well as being fundamental to exploratory activities (Raisch Birkinshaw, Probst, \& Tushman, 2009).

Although a lack of agility at the institutional level is already a concerning phenomenon in a wider environment characterised by exponential change, it is especially disquieting when combined with the belief expressed by half of participants that time is still in the industry's favour. The attitude echoes the downfall of Kodak less than a decade ago (Reeves, Hannaes, \& Sinha, 2015) or DEC in the 1980s (Lewis, 2019). Looking at the adjacent, and oftentimes overlapping, financial sector, regulators have increasingly had their hands forced by the rapid changes introduced by FinTech (Arner, Barberis, \& Buckley, 2017). Although it may be tempting for leaders to opt for a 'wait and see' or more measured approach, the lack of agility voiced by participants, when coupled with fading industry protection mechanisms, strongly indicates the need for organisations to change their mindsets. The prominent theme of partnerships and ecosystems among participants indicates that at least at an individual level, leaders have an idea of what that new mindset would look like for their industry to contend with the impacts of the 4IR.

The theme of adopting a partnership mindset is in line with the recommendations in the literature for incumbents to continue developing within the changing industry environment - something that is already being leveraged within the financial services industry (Curran, Garrett, \& Puthiyamadam, 2017; Kane, Palmer, Phillips, Kiron, \& Buckley, 2015). Further, the desire for collaboration expressed by participants demonstrates broad acceptance that the industry does not possess the expertise needed to innovate internally and that cross-industry networks are therefore valued for the expertise they offer. However, juxtaposed 
against the desire to partner, participants presented a strong protectionist attitude that inhibits collaboration. This attitude appeared to be powerfully influenced by organisational leadership, which sets the tone for how partnership is interpreted across the organisation. Although participants said that leadership was supportive of adopting a partnership mindset, they said that, in practice, leadership was inconsistent. In other words, although leaders recognise that partnerships are needed to access the relevant technological expertise, they are hesitant to prioritise collaborative projects because they are afraid to lose ground on core business.

Participants acknowledged that people were a key enabler of successful organisational change in terms of the 4IR, particularly in relation to exploration and innovation efforts. This is consistent with literature findings that emphasise the important role people play in unlocking the 4IR innovation within organisations (Davis, 2016; Schwab, 2016a). Indeed, any form of organisational change of the magnitude projected by the 4IR requires great focus on individual-level factors (Bovey \& Hede, 2001b; Singh et al., 2012). Embracing the potential of individuals could equip the life insurance industry to adapt to the changing industry context. The skills shortage in the country, however, may be inhibiting organisations from adopting this strategy. This introduces the risk that organisations might exploit the partnership and ecosystems approach to the extent that they look to the external system exclusively for accessing technical expertise. Following this approach, organisations would forgo internal capacity-building and people development in favour of acquiring human capital, contracting experts or outsourcing with the hope that external skillsets will be sufficient to drive innovation. However, this approach does not support the culture of continuous learning recommended by various authors (Gratton, 2011; Shook \& Knickrehm, 2017). To develop the capability to embrace the changing work environment, leaders will have to adopt ambidextrous behaviours that encourage creativity and innovation (Poon \& Mohamad, 2020).

\section{Practical implications}

By seeing the 4IR as an institutional transformation that organisations are empowered to lead, South African life insurers should recognise that the role of people in innovation extends beyond technical skills. By proactively maintaining and cultivating an array of relevant skills within their workforce, such as creative intelligence and social intelligence skills, organisations can develop employees who are more adaptable (World Bank, 2019). This will allow both employees and the organisation to secure their continued relevance in the industry. This more expansive view of the value of individuals could allow organisations to reframe many of the industry dynamics that they currently view as inhibitors, as opportunities. For instance, where the actuarial focus of the industry is currently cited as an inhibitor of change because of its risk aversion, the data-driven aspect of actuarial science presents an enormous opportunity for introducing InsurTech related to data analytics. Organisations can use such institutional traits that have given them advantages in the traditional industry to innovate new advantages within the 4IR era of the industry.

In fact, recognising the potential for technology integration within the actuarial stronghold of the industry might be key for organisations and leaders to see the 4IR for what it is: an institutional jolt that will fundamentally change the field. As the 4IR technologies propagate throughout the greater economy, value chains will become more nuanced and complex, leading to the need for increased specialisation and partnerships between unlikely actors. If life insurance organisations want to leverage the expertise of others in the insurance ecosystem, they will need to undergo a mindset shift from zero sum to openness. The need to mitigate risk aversion does not imply that firms should extravagantly pursue unnecessary risk; it demands that firms align the risk appetite of people in the organisation with the degree of change required by the external environment. Similarly, developing true partnerships does not mean blindly disregarding fairness and obligations, but rather appreciating the unique valuecreation that can only be achieved through collaboration with a diverse group of stakeholders and organisations.

\section{Recommendations}

As this study relied on leaders within insurance firms to identify the perceptions of their organisations, additional studies might build on these findings to understand if or how these perceptions are shared and how those perceptions are enacted in ways of working. A more in-depth case study of this kind would be useful to identify specific opportunities for introducing change within organisations. An examination of individual resistance to change, in line with Singh et al. (2012) and Bovey and Hede (2001a, 2001b), related to specific elements of the 4IR would be useful for pinpointing the exact concerns within this workforce. It may help illuminate or dispel certain elements of cultural inertia cited in this study, such as risk aversion or zero-sum mindsets, to identify possible solutions for making the workforce more receptive to change.

\section{Conclusion}

This study affirms the view that the South African life insurance lacks agility in responding to the 4IR changes and sheds greater light on the mechanisms of resistance to change at the organisational and individual levels of the industry. The findings indicate that life insurance companies in South Africa are limiting themselves by focussing on external factors as inhibitors rather than catalysts of innovation and viewing the $4 \mathrm{IR}$ as a set of tools rather than a technological transformation.

Technology speed, processing power and cost improvements continue to reinforce the inevitability that algorithms will perform increasingly complex tasks better than humans. Ignoring threats of change or opportunities for introducing 
incremental change are clear routes to irrelevance. The means to sustain both human and business relevance is the adoption of a continuous learning mindset, which the 4IR innovations may be instrumental in facilitating. The sooner organisations and their leaders recognise this, the more proactive they can be in embracing the 4IR.

\section{Acknowledgements Competing interests}

The authors have declared that no competing interest exists.

\section{Author's contributions}

L.M. conceptualised and conducted the research. L.R. supervised the study and prepared the manuscript for submission.

\section{Ethical considerations}

Ethical clearance for the study was granted by the University of Cape Town, Graduate School of Business Ethics Committee (2018-902). Written informed consent was obtained from the participants to conduct structured interviews and include their anonymous data in this study. To ensure confidentiality, pseudonyms were used in the reporting of these findings.

\section{Funding information}

The authors received no financial support for the research, authorship and/or publication of this article.

\section{Data availability}

The data that support the findings of this study are available on request from the corresponding author (L.R.). The data are not publicly available because they contain information that could compromise the privacy of research participants.

\section{Disclaimer}

The views and opinions expressed in this article are those of the authors and do not necessarily reflect the official policy or position of any affiliated agency of the authors.

\section{References}

Adler, P.S., Benner, M., James, D., Paul, J., Osono, E., Staats, B.R., Takeuchi, H., Tushman, M. L., \& Winter, S.G. (2009). Perspectives on the productivity dilemma. Journal of Operations Management, 27(2), 99-113. https://doi.org/10.1016/j. jom.2009.01.004

Arner, D.W., Barberis, J., \& Buckley, R.P. (2015). The evolution of Fintech: A new postcrisis paradigm. Georgetown Journal of International Law, 47, 1271. https://doi. crisis paradigm. Georgetow
org/10.2139/ssrn.2676553

Arner, D.W., Barberis, J., \& Buckley, R.P. (2017). FinTech, RegTech, and the reconceptualization of financial regulation. Northwestern Journal of International Law \& Business, 37(3), 371-413.

Axco. (2018). Insurance market report: South Africa - Life and benefits. London: Axco Insurance Information Services.

Bender, M., \& Willmott, P. (2017). Digital reinvention. Retrieved from https://www. mckinsey.com/business-functions/digital-mckinsey/our-insights/digital-reinvention

Bernstein, A., \& Raman, A. (2015). The great decoupling. Harvard Business Review, 93(6), 66-75.
Bose, A., \& Bastid, V. (2018). World Insurance Report 2018. Retrieved from https:// worldinsurancereport.com/resources/world-insurance-report-2018/

Bovey, W.H., \& Hede, A. (2001a). Resistance to organizational change: The role of defence mechanisms. Journal of Managerial Psychology, 16(7), 534-548. https:// doi.org/10.1108/EUM0000000006166

Bovey, W.H., \& Hede, A. (2001b). Resistance to organizational change: The role of cognitive and affective processes. Leadership \& Organization Developmen Journal, 22(8), 372-382. https://doi.org/10.1108/01437730110410099

Bryman, A., \& Bell, E. (2015). Business research methods (3rd edn.). New York, NY: Oxford University Press.

Bughin, J., Laberge, L., \& Mellbye, A. (2017). The case for digital reinvention. Retrieved from https://www.mckinsey.com/business-functions/digital-mckinsey/ourinsights/the-case-for-digital-reinvention

Camarate, J., Smit, V., Van Rooyen, R., \& Chimbuya, A. (2017). Life insurance in the digital age: The omnichannel revolution. Retrieved from https://www.pwc.co.za/ en/publications/strategy-and.html

Canning, J., \& Found, P.A. (2015). The effect of resistance in organizational change programmes: A study of a lean transformation. International Journal of Quality and Service Sciences, 7(2/3), 274-295. https://doi.org/10.1108/IJQSS-02-2015-0018

Catlin, T., \& Lorenz, J.-T. (2017). Digital disruption in insurance: Cutting through the noise. Retrieved from https://www.mckinsey.com/industries/financial-services/ our-insights/digital-insurance

Chetty, K. (2018). Future of work in South Africa: The road to 2030. Retrieved from https://economic-policy-forum.org/wp-content/uploads/2016/10/ FutureOfWork-SA-Country-Report-20181008.pdf

Chetty, K. (2018). The future of work in South Africa. South Africa: Mimeo, Human Sciences Research Council - Emerging Markets Sustainability Dialogues.

Coetzee, C.J.H., \& Stanz, K.J. (2015). 'Barriers-to-change' in a governmental service delivery type organisation. SA Journal of Industrial Psychology, 33(2), 76-82. delivery type organisation. SA Journal
https://doi.org/10.4102/sajip.v33i2.380

Creswell, J.W. (2013). Qualitative inquiry and research design: Choosing among five approaches (3rd edn.). Thousand Oaks, CA: Sage Publications.

Curran, C., Garrett, D., \& Puthiyamadam, T. (2017). A decade of digital: Keeping pace with transformation. Retrieved from https://www.pwc.com/ee/et/publications/ pub/pwc-digital-iq-report.pdf

Davis, E. (2016). People - Not just machines - Will power digital innovation: Keep challenging. Retrieved from https://www.cognizant.com/futureofwork/ whitepaper/people-not-just-machines-will-power-digital-innovation

Deloitte. (2019a). The Deloitte global millennial survey 2019: Societal discord and technological transformation create a 'generation disrupted'. Retrieved from https://www2.deloitte.com/za/en/pages/about-deloitte/articles/ millennialsurvey.html

Deloitte. (2019b). 2019 Deloitte global millennial survey: A 'generation disrupted' South Africa results. Retrieved from https://www2.deloitte.com/content/dam/ Deloitte/za/Documents/about-deloitte/za_deloitte_may_2019_millennials south_africa_report_f.pdf

Deloitte. (2019c). Success personified in the fourth industrial revolution: Four leadership personas for an era of change and uncertainty. Retrieved from https:// www2.deloitte.com/content/dam/insights/us/articles/GLOB1948 Successpersonified-4th-ind-rev/DI_Success-personified-fourth-industrial-revolution.pdf

Dessus, S.C., Goddard, J.G., \& Hanush, M. (2017). South Africa economic update Innovation for productivity and inclusiveness. Retrieved from http://documents1. worldbank.org/curated/en/779551505322376708/pdf/119695-WP-PUBLIC-SAEU-2017-Digital-Version-Sep-19.pdf

DiMaggio, P.J., \& Powell, W.W. (1983). The iron cage revisited: Institutional isomorphism and collective rationality in organizational fields. American Sociological Review, 48(2), 147-160. https://doi.org/10.2307/2095101

Dorado, S. (2002). Institutional entrepreneurship, partaking, and convening. OrganizationStudies, 26(3),385-414.https://doi.org/10.1177/0170840605050873

Frey, C.B., \& Osborne, M.A. (2017). The future of employment: How susceptible are jobs to computerisation? Technological Forecasting and Social Change, 114, 254-280. https://doi.org/10.1016/j.techfore.2016.08.019

Gratton, L. (2011). The shift: The future of work is already here. London: Harper Collins.

Guest, G., Bunce, A., \& Johnson, L. (2006). How many interviews are enough? An experiment with data saturation and variability. Family Health International, 18(1), 59-82. https://doi.org/10.1177/1525822X05279903

Hinings, C.R., Greenwood, R., Reay, T., \& Suddaby, R. (2004). Dynamics of change in organizational fields. In M.S. Poole \& A.H. Van de Ven (Eds.), Handbook of organizational change and innovation (pp. 304-323). New York, NY: Oxford University Press.

Holliday, S. (2019). How insurtech can close the protection gap in emerging markets. Retrieved from https://www.the-digital-insurer.com/wp-content/ uploads/2019/09/1581-EMCompass-Note-70-InsurTech.pdf

Independent Communications Authority of South Africa. (2018). 3rd Report on the state of the ICT sector in South Africa. Retrieved from https://www.icasa.org.za/ uploads/files/State-of-ICT-Sector-Report-March-2018.pdf

Kane, G.C., Palmer, D., Phillips, A.N., Kiron, D., \& Buckley, N. (2015). Strategy, not technology, drives digital transformation: Becoming a digitally mature enterprise. Retrieved from https://sloanreview.mit.edu/projects/strategy-drives-digitalRetrieved from

King, N., \& Brooks, J.M. (2017). Template analysis for business and management students. London: Sage. 
Kuusisto, M. (2017). Organizational effects of digitalization: A literature review. International Journal of Organization Theory and Behavior, 20(3), 341-362. https://doi.org/10.1108/IJOTB-20-03-2017-B003

Leedy, P.D., Ormrod, J.E., \& Johnson, L.R. (2019). Practical research: Planning and design (12th edn.). Essex: Pearson Education Limited.

Lewis, M.S. (2019). Technology change or resistance to changing institutional logics: The rise and fall of Digital Equipment Corporation. Journal of Applied Behavioral Science, 5(2), 141-160. https://doi.org/10.1177/0021886318822305

Lord, R.G., Dinh, J.E., Hoffman, E.L., \& Burke, E. (2015). A quantum approach to time and organizational change. Academy of Management Review, 40(2), 263-290. https://doi.org/10.5465/amr.2013.0273

Malherbe, A., \& Dixon, G. (2017). The South African insurance industry survey 2017: Evolve. Retrieved from https://assets.kpmg/content/dam/kpmg/za/ pdf/2017/08/2017-insurance-survey.pdf

Moodley, A.J. (2019). Digital transformation in South Africa's short-term insurance sectors: Traditional insurers' responses to the internet of things (IOT) and insurtech. The African Journal of Information and Communication, 24, 1-16. insurtech. The African Journal of Inform
https://doi.org/10.23962/10539/28657

Okada, F. (2018). Business model changes through collaborative dynamic capabilities through insurance company use of IT (InsurTech) in the medical and health
sectors. In M. Kodama (Ed.), Collaborative dynamic capabilities for service innovation (pp. 153-162). London: Palgrave Macmillan.

Peters, M.A. (2017). Technological unemployment: Educating for the fourth industrial revolution. Journal of Self-Governance and Management Economics, 5(1), 25-33. https://doi.org/10.22381/JSME5120172

Poon, W.C., \& Mohamad, O. (2020). Organisational context and behavioural complexity affecting ambidextrous behaviours among SMEs. International Journal of Organization Theory \& Behavior, 23(3), 225-244. https://doi.org/10.1108/ |JOTB-03-2019-0037

Quinlan, C., Babin, B., Carr, J., Griffin, M., \& Zikmund, W.G. (2015). Business research methods. Hampshire: Cengage Learning.

Raisch, S., Birkinshaw, J., Probst, G., \& Tushman, M.L. (2009). Organizationa ambidexterity: Balancing exploitation and exploration for sustained performance. Organizational Science, 20(4), 685-695. https://doi.org/10.1287/ orsc.1090.0428
Reeves, M., Hannaes, K., \& Sinha, J. (2015). Your strategy needs a strategy: How to choose and execute the right approach. Boston, MA: Harvard Business Review Press.

Roblek, V., Meško, M., \& Krapež, A. (2016). A complex view of industry 4.0. Sage Open, 6(2), 1-11. https://doi.org/10.1177/2158244016653987

Schwab, K. (2016a). The fourth industrial revolution. Geneva: World Economic Forum. Geneva.

Schwab, K. (2016b). The fourth industrial revolution: What it means, how to respond. Retrieved from https://www.weforum.org/agenda/2016/01/the-fourthindustrial-revolution-what-it-means-and-how-to-respond

Shook, E., \& Knickrehm, M. (2017). Harnessing revolution: Creating the future workforce. Retrieved from https://www.accenture.com/ acnmedia/pdf-40/ accenture-strategy-harnessing-revolution-pov.pdf

Singh, K., Saeed, M., \& Bertsch, A. (2012). Key factors influencing employee response toward change: A test in the telecom industry in India. Journal of Management Policy and Practice, 13(3), 66-68.

Spelman, M., \& Weinelt, B. (2018). Digital transformation initiative. Retrieved from http://reports.weforum.org/digital-transformation

Swiss Re. (2017). Insurance: Adding value to development in emerging markets. Retrieved from https://www.swissre.com/dam/jcr:0c654530-302f-4442-b01e585d11ea3beb/sigma4_2017_en.pdf

Statistics South Africa. (2019). Quarterly labour force survey: Quarter 1 2019. Retrieved from http://www.statssa.gov.za/publications/P0211/P02111stQuarter2019.pdf.

Tushman, M.L., O'Reilly, C.A., \& Harreld, B. (2015). Leading proactive punctuated change: An organizational perspective. In R. Henderson, R. Gulati, \& M.L. Tushman (Eds.), Leading sustainable change (pp. 249-270). London: Oxford University Press.

Whysall, Z., Owtram, M., \& Brittain, S. (2019). The new talent management challenges of Industry 4.0. Journal of Management Development, 38(2), 118-129. https:// doi.org/10.1108/JMD-06-2018-0181

World Bank. (2018). South African economic update. Retrieved from http://pubdocs. worldbank.org/en/798731523331698204/South-Africa-Economic-UpdateApril-2018.pdf

World Bank. (2019). 2019 World development report: The changing nature of work. Retrieved from http://dc.sourceafrica.net/documents/119029-2019World-Development-Report-The-Changing.html 
TABLE A1: Interview questionnaire.

\section{Number Question}

A1. Briefly describe your role and responsibilities.

\section{Section 1: Industry}

A2. What do you understand by the term, the Fourth Industrial Revolution?

A3. How do you feel that the Fourth Industrial Revolution is affecting the South African life insurance industry?

\section{Section 2: Company}

A4. Describe your organisation's vision in your own words.

A5. Do you find this vision compelling? Please explain.

A6. Do you believe that the vision is accepted as compelling within the broader staff base? Please explain.

A7. Does your organisation's vision support keeping up with technological change?

A8. Does your organisation's vision support initiating radical technological change?

A9. Is your organisation's vision regularly communicated to staff?

A10. What are your thoughts on your organisation's ability to balance incremental technological change "(process optimisation/exploiting existing products/services)' and radical technological change '(exploring new, potentially disruptive innovations or opportunities)?

A11. Does your organisation have a deeply entrenched organisational culture?

A12. Does your organisation actively support risk-taking in relation to digital initiatives?

A13. Within your organisation, are decisions made quickly in relation to digital initiatives?

A14. Does your organisational culture support both incremental technological change and disruptive innovation efforts?

A15. Do cultural differences exist between established business units and those involved in innovation efforts?

Section 3: Leadership

A16. Does executive leadership in my organisation have a clear focus on keeping up with technological change?

A17. Does executive leadership in my organisation have a clear focus on initiating radical technological change?

A18. Is the technology innovation agenda driven by the CEO and senior executive team?

CEO, chief executive officer. 